\title{
Circularity in ethotic structures
}

\author{
Katarzyna Budzynska
}

Received: 28 August 2011 / Accepted: 6 June 2012 / Published online: 24 June 2012 (C) The Author(s) 2012. This article is published with open access at Springerlink.com

\begin{abstract}
The aim of this paper is to provide a model that allows the representation and analysis of circularity in ethotic structures, i.e. in communication structures related to the speaker's character and in particular, his credibility. The paper studies three types of cycles: in self-referential sentences, embedded testimony and ethotic begging the question. It is shown that standard models allow the reconstruction of the circularities only if those circular utterances are interpreted as ethotic arguments. Their alternative, assertive interpretation requires enriching the existing models with a purely ethotic component related to the credibility of the performer of any (not necessarily argumentative) speech act.
\end{abstract}

Keywords Argumentation theory - Argumentation schemes - Ethotic argument · Dialogue $\cdot$ Circular reasoning $\cdot$ Circular reference $\cdot$ Ethos $\cdot$ Credibility of speaker

\section{Introduction}

The aim of the paper is to provide a model that allows the representation and analysis of circularity in ethotic structures. The concept of ethos was introduced in Aristotle's Rhetoric (1991). Amongst the means of persuasion, he distinguishes logos, an argument delivered in speech; pathos, which is related to the influence on the emotional state of the hearer; and ethos, which is related to the character of the speaker and in particular, his credibility. In modern argumentation theory, the elements of ethos are studied as ethotic argument (Brinton 1986), interpersonal argumentation (Budzynska 2010) or source indicators reasoning (Walton 1998):

K. Budzynska ( $\square)$

Institute of Philosophy and Sociology, Polish Academy of Sciences, Warsaw, Poland

e-mail: budzynska.argdiap@gmail.com 
In the appeal to expert opinion, an argument is judged to have greater plausibility on the grounds that the arguer has positive ethos, because she is supposedly an expert. In the ad hominem argument, the arguer is attacked on the grounds that she has negative ethos (bad character) (Walton 1999, p. 183).

The paper studies three types of cycles in ethotic structures: self-referential sentences, embedded testimony and ethotic begging the question. When the speaker refers to his own credibility, he commits a fallacy of ethotic self-referential circularity. In embedded testimony, one speaker $i$ evokes an other speaker's testimony to confirm $i$ 's own credibility; however, in order to accept this testimony, $i$ 's own testimony and credibility have to be accepted beforehand. Ethotic begging the question (analysed by, e.g. Hamblin (1970); Walton (2006)) is a fallacy of cyclic argumentation in which a speaker $i$ 's credibility is supported by another speaker $j$ 's credibility and then $j$ 's credibility is supported by $i$ 's credibility.

It is shown that standard models allow the reconstruction of these circularities only if the circular utterances are interpreted as acts of argumentation. For example, the self-referential sentence "I'm credible" can be claimed to be circular, because what the speaker meant in performing this act was in fact to prove his credibility. In other words, according to an argumentative interpretation, the circularity of this sentence can be explained if the speaker is assumed to perform the circular argument, "I'm credible, because I'm credible". Yet an alternative, non-argumentative interpretation of these utterances is also possible, i.e. the self-referential sentence may be understood only as an act of simple assertion. In order to represent the circularity of these utterances in an assertive interpretation, existing models need to be extended and a purely ethotic component has to be introduced. This component refers to a basic phenomenon in communication: that in the evaluation of a message, the speaker's credibility is assessed. Therefore, the component should not be limited to the performance of ethotic argument, for a message can be delivered by means of different speech acts, e.g. an assertion or an order, not necessarily by an argumentation (see e.g. Budzynska and Kacprzak 2008).

The paper is structured as follows. In Sect. 2, two interpretations of ethotic circular utterances: argumentative and assertive, are discussed. Section 3 gives a brief overview of Inference Anchoring Theory which in Sect.4 is used to propose a new model that allows the representation of circularity which does not depend upon an argumentative interpretation of ethotic utterances. Finally, Sect. 5 presents how this model allows the identification of different types of ethotic circularities in Hamblin's well-known example of ethotic begging the question.

\section{Reconstructing circularity in ethotic utterances}

In this section, two possible reconstructions of circularity in ethotic utterances are discussed. It will be shown that while standard models allowed ethotic cycles to be represented under argumentative interpretations of such utterances, the same is not possible if the utterances are interpreted as acts of simple assertion. Here, two types of ethotic circularity are analysed: self-referential sentences and embedded testimony. 
Traditionally, philosophy has examined only ethotic self-referential sentences which lead to liar paradoxes (cf. Beall and Glanzberg 2011). Yet not only liars but also truthful speakers may cause problems of self-reference. Consider the following utterance:

a. Bob said, I'm credible.

Intuitively, in order to accept what the speaker asserts, the hearer has to assume that the speaker does not lie to him, i.e. he has to assume the speaker's credibility. As a result, in (1-a) in order to accept what Bob asserted, i.e., that Bob is credible, the hearer has to assume Bob's credibility beforehand. In this way, Bob's utterance generates a cycle.

Reporting on someone's testimony about a speaker's credibility also commits a fallacy of ethotic circularity:

a. Bob said, Ann said I'm credible.

The circularity of embedded testimony can be described in the following way: Bob's credibility is dependent on Ann's testimony and credibility, which in turn is dependent on Bob's credibility, because the hearer has to accept that Bob did not mislead him about what Ann said, i.e., Ann really testified that Bob is credible.

\subsection{Argumentative interpretation}

One possible representation of circularity in utterances (1-a) and (2-a) is to interpret them as argumentative speech acts. In this case, it can be claimed that (1) commits the fallacy of equivalency begging the question and (2) commits the fallacy of dependency begging the question (Woods and Walton 1975). ${ }^{1}$

More specifically, it can be claimed that in order to properly represent the example (1), it has to be analysed in the context of the dialogue's history. That is, Bob does not just assert something about himself, but he responds to doubts about his credibility expressed earlier by another participant of a dialogue. According to such an interpretation, the cycle in his utterance will be obtained only if we assume that Bob did not only assert that he is credible, but he also performed an argument in which he is supporting his credibility with his credibility.

The argumentative interpretation of acts of simple assertion can be found in various works in the area of argumentation theory. Consider as an example the dialogue from (Walton 1996, p. 149):

a. Tourist said, Excuse me, could you tell me how to get to the Convention Center?

\footnotetext{
${ }^{1}$ In equivalency begging the question, "a premise of an argument is either the same proposition as the conclusion to be proved, or is equivalent to it, meaning that it represents the same proposition even though the wording of the two sentences expressing the proposition is different" (Walton 2006, p. 247). In dependency begging the question, "one of the premises depends on the conclusion, meaning that the line of reasoning used to support the premise requires the conclusion as a part of the reasoning" (Walton 2006, p. 248). Moreover, in the paper the dialectical account of begging the question is assumed, i.e. it is assumed that this fallacy can be properly represented in a framework of a dialogue, cf. (Walton 2006).
} 
b. Passerby said, Yes. Just go straight down Portage Avenue in this direction [indicates]. It is about eight blocks or so. Then turn to the right on Edmonton Street. It is only three blocks or so from Portage.

The Passerby's information about the route to the Convention Center is analysed as an example of argumentation from position to know. Here, it is assumed that the Tourist may infer a conclusion about how to get to the Convention Center on the basis of the Passerby's assertion (3-b) and the Passerby's credibility (in this case, his position to know). ${ }^{2}$ That is, according to Walton the utterance (3-b) is in fact an act of argumentation that could be reconstructed in the following way: "The Tourist will get to the Convention Center if he goes straight down Portage Avenue for about eight blocks or so and then turn to the right on Edmonton Street; since the Passerby said that the Tourist will get to the Convention Center if he goes straight down Portage Avenue for about eight blocks or so and then turn to the right on Edmonton Street; and the Passerby is in position to know how to get to the Convention Center".

A model that allows representation of the circularity in (1-a) and (2-a) under an argumentative interpretation is, e.g., the theory of argumentation schemes described in (Walton 1996; Walton and Reed 2005; Walton et al. 2008). We will use a version of ethotic argument slightly modified for the needs of the clarity of the paper (Walton et al. 2008, p. 336): ${ }^{3}$

\section{ETHOTIC ARGUMENT SCHEME}

\section{$i$ said $A$.}

$i$ is credible.

Therefore, $A$ should be accepted as more plausible.

In the ethotic argument scheme, from a speech act with the propositional content $A$ and the credibility of the speaker, the content $A$ may be inferred.

According to the argumentative interpretation of Bob's assertion and the introduced scheme for ethotic argument, (1-a) can be reconstructed in a following way:

\section{Argument (Arg1)}

(Concl) Bob is credible.

$\left(\mathrm{P}_{1}\right)$ Bob said that, Bob is credible.

$\left(\mathrm{P}_{2}\right)$ Bob is credible.

\footnotetext{
2 In (Walton 1996) various arguments appealing to the speaker's character are considered. Two main types, called argument from position to know and ethotic argument, refer to two main components of Aristotelian ethos (Aristotle 1991, II.1): the speaker's practical wisdom (described in the position-to-know scheme in a premise " $i$ is in a position to know whether what he asserts is true or not") and the speaker's natural virtue (described in the ethotic scheme in a premise " $i$ is a person of good (bad) moral character").

3 The original version of ethotic argument has a following scheme: If $i$ is a person of good (bad) moral character, then what $i$ says should be accepted as more plausible (rejected as less plausible); and $i$ is a person of good (bad) moral character; therefore, what $i$ says should be accepted as more plausible (rejected as less plausible). For the clarity of the analysis, we use its modified version. First, the scheme is enriched by an implicit premise reporting on what the speaker uttered (" $i$ said $A$ "). Moreover, only good moral character of the speaker is considered and it is identified with the speaker's credibility. Finally, the conditional premise "If $i$ is a person of good (bad) moral character, then what $i$ says should be accepted as more plausible (rejected as less plausible)" is left implicit.
} 
The argumentative interpretation of (1-a) assumes that Bob provides a premise "I'm credible" $\left(\mathrm{P}_{2}\right)$ to support his credibility $(\mathrm{Concl})$. Moreover, his utterance "I'm credible" constitutes another premise of the argument $\left(\mathrm{P}_{1}\right)$. The cycle is obtained in the argumentative structure, since $(\mathrm{Concl})$ and $\left(\mathrm{P}_{2}\right)$ are the same sentence: "Bob is credible". In other words, Bob commits the fallacy of ethotic circularity, if in saying "I'm credible" he performs two speech acts at the same time, i.e. he asserts that he is credible: $\left(\mathrm{P}_{2}\right)$, and he (circularly) argue for his credibility: (Arg1).

Similarly, representing Bob's and Ann's utterances as speech acts of argumentation allows the circularity to be reconstructed in the analysis of (2). According to Walton's scheme of ethotic argument, (2-a) has the following form (where a proposition in a subitem is a premise of a proposition expressed in its superior item):

\section{Argument (Arg2)}

(Concl) Bob is credible.

$\left(\mathrm{P}_{1}\right)$ Ann said that Bob is credible.

$\left(\mathrm{P}_{2}\right)$ Ann is credible.

$\left(\mathrm{P}_{1.1}\right)$ Bob said Ann says that Bob is credible.

$\left(\mathrm{P}_{1.2}\right)$ Bob is credible.

Assume that in saying "Ann says I'm credible", Bob tries to prove his credibility. As a result, the main conclusion of Bob's argument (Arg2) is "Bob is credible" (Concl). What is given as an evidence for accepting his credibility is Ann's testimony $\left(\mathrm{P}_{1}\right)$ and the assumption that she can be trusted as a credible witness $\left(\mathrm{P}_{2}\right)$. Further, the arguments for accepting that Ann's testimony has really taken place $\left(\mathrm{P}_{1}\right)$ are Bob's testimony on it $\left(\mathrm{P}_{1.1}\right)$ and the assumption that he can be trusted $\left(\mathrm{P}_{1.2}\right)$. The utterance $(2-\mathrm{a})$ commits the fallacy of dependency begging the question, since there is an (indirect) cycle in which Bob's credibility (Concl) is supported with Bob's credibility $\left(\mathrm{P}_{1.2}\right)$.

In such a way, ethotic circularity of self-referential sentence and embedded testimony can be reconstructed if the argumentative reading of those utterances is assumed. Yet should not their assertive interpretation be also allowed, i.e., could we not assume that in (1-a) Bob's simply asserts that he is credible and in (2-a) he just reports on Ann's testimony not trying to prove anything at the same time? But then, does logic or philosophy of language provide a model that allows the representation of those circularities? Those questions will be discussed in the next section.

\subsection{Assertive interpretation}

The first question we want to ask now is whether a different interpretation of utterances like (1-a) and (2-a) is possible. That is, can they be understood just as acts of simple assertion? Assume that Bob initiated a discussion by saying "I'm credible," in the same way that he could start a dialogue with an utterance, "I spent my last holidays in Thailand". In other words, (1-a) might not have been a response to an earlier challenge, "Why should I believe that you are credible?". Bob could have simply wanted to give some information about himself (e.g., where he spent holidays, or whether he is credible). In such a case, (1-a) is interpreted assertively. 
Giving that an assertive interpretation of (1-a) and (2-a) is possible, the next question is whether those assertions are still structurally circular? Compare the two assertions: "Bob said, I spent my last holiday in Thailand" and "Bob said, I'm credible". In the first case, in order to accept that Bob spent his last holiday in Thailand, we have to believe him; believe that he is credible. Similarly, in order to accept the content of Bob's assertion about his credibility, we have to assume that we can believe him (i.e., that he is credible). As a result, even if (1-a) is interpreted assertively, the utterance is circular, for to accept Bob's credibility (what he asserted) already his credibility has to be assumed.

The last question addressed in this section is how the structural circularity of (1-a) and (2-a) can be represented. One possibility is to draw on the analogy of the analysis of the liar paradox: for both, "I'm a liar" and "I'm credible" are self-referential sentences. Consider the Simple-falsity Liar case (Beall and Glanzberg 2011). In the analysis, the sentence " $p: p$ is false" is replaced with the sentence:

$$
p: p \text { is true }
$$

Unlike the liar case, this sentence does not lead to contradiction, since if " $p$ is true" is true, then $p$ is true. The analogy obviously fails, for those two types of selfreferential sentences commits different fallacies (circularity vs. self-contradiction). Yet the problem remains: how can the sentence legitimately provide the information about its own logical value, if the valuation is dependent upon that value?

Another possibility is to apply Inference Anchoring Theory, IAT (Budzynska and Reed 2011) which models the deep structure not only of argumentative speech acts (to which argumentation theory is restricted), but of any speech act. In particular, it allows the representation of a relation between the speech act and its propositional content, together with the link to ethotic obligations placed on the performer of this speech act. The next section demonstrates how IAT can be used to reconstruct ethotic circularity under an assertive interpretation.

\section{Where is ethos?}

We showed that it is not just ethotic arguments that can be structurally circular (committing, as a result, the fallacy of begging the question), but also simple assertions that can create ethotic cycles. As far as we are aware, there is no standard model that allows the reconstruction of circularity under an assertive interpretation of ethotic utterances such as (1-a) and (2-a). In this paper, we propose how to represent such ethotic circularities building on a recently introduced model called Inference Anchoring Theory, IAT (Budzynska and Reed 2011). In the next section, we will show how IAT can be used to describe non-argumentative ethotic cycles, but first the relevant parts of the theory will be briefly summarized.

\subsection{Connecting utterances with their contents}

Inference Anchoring Theory allows the description of different communication phenomena related to reasoning and dialogue and the modelling of interactions amongst 
them. The main motivation for developing IAT was to explain how the complex language structures (particularly inference) are linked to communicative structures (such as e.g. speech acts of argumentation or explanation) building on theories of dialogue protocols such as (Reed 2006). Therefore, the concept of illocutionary connection was introduced. The main idea of IAT will be sketched using an example of argument from negative consequences from (Walton 2009, p. 55):

(4) a. Bob said, You should not eat too much salt.

b. Wilma said, Why?

c. Bob said, Because eating too much salt has the consequence of raising blood pressure.

If we focus only on inferential structures, the dialogue (4) contains a reasoning consisting of a conclusion "Wilma should not eat too much salt"; premises (one premise is implicit, both in the dialogue and its diagram in Fig. 1) "Eating too much salt has the consequence of raising blood pressure"; and an inference which follows the pattern of argument from negative consequences. Diagrammatically, instances of inference schemes correspond to rule nodes (see the node labelled argument from consequences instance \#1 in Fig. 1, (Reed et al. 2007).

On the other hand, if we focus on dialogical (communicative) structures, (4) contains three utterances (speech acts) whose performance is governed by dialogue rules corresponding diagrammatically to transition nodes (see e.g. the node labelled transition instance \#1 in Fig. 1) (Reed et al. 2010). The dialogue rules may have a more infor-

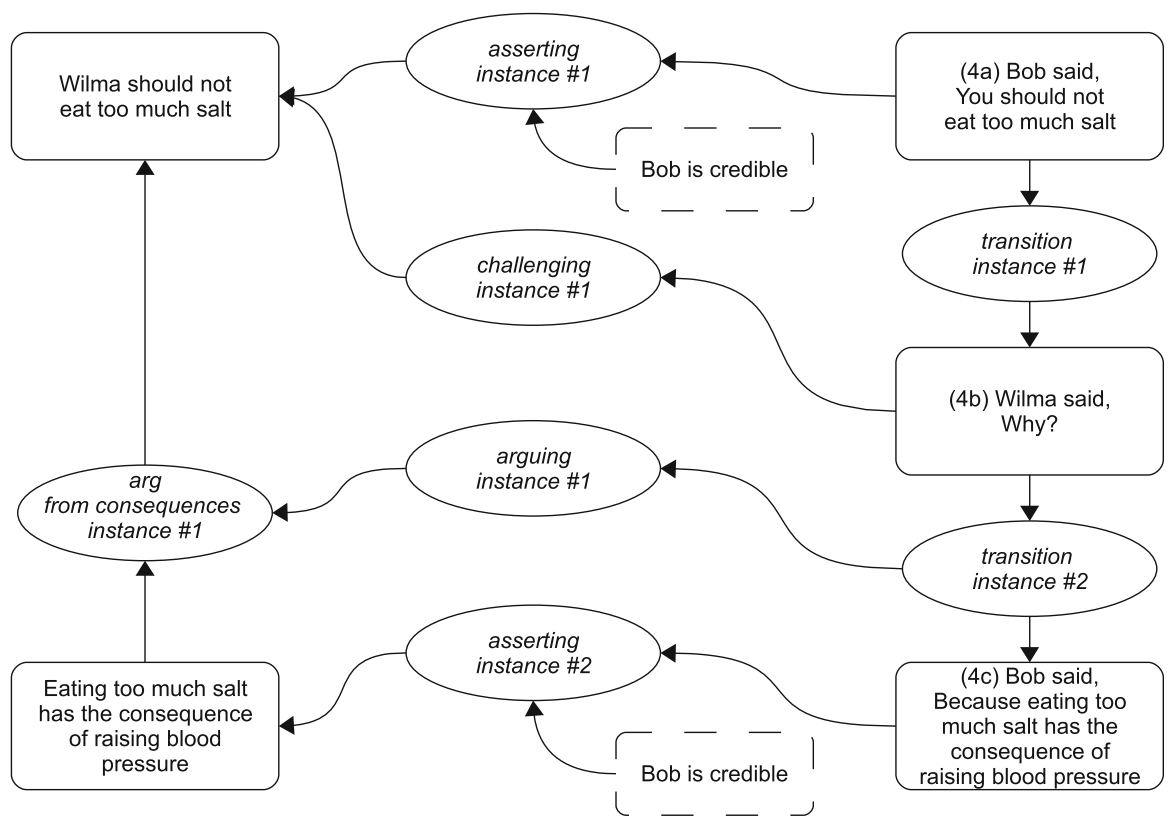

Fig. 1 Dialogue, argumentation and the interaction between them 
mal character (as in natural discourse) or a more formal character (as described by a protocol in dialogue games, see e.g. (Prakken 2006).

Inferential (language) structures are linked, generated and "anchored" in communicative structures via illocutionary connections. The communication acts in a dialogue (e.g. "Bob said, Wilma should not eat too much salt") have their propositional contents in the dialogue domain (e.g. "Wilma should not eat too much salt"). In IAT, the relations between the inferential structures and dialogical structures are assumed to be linked together by illocutionary connections (e.g. the node asserting instance \#1 in Fig. 1), related to the illocutionary force (see e.g. Searle 1969) and linking a communication act in a dialogical structure with its content in an inferential structure.

The illocutionary force of an utterance can be of a number of types (assertive, directive, etc.). What type of force should be associated with a given speech act is dependent on the constitutive rules (Searle 1969). For example, in order for the connection to be reconstructed as assertive, the utterance has to be a felicitous assertion. In particular, it has to satisfy the constitutive rule of sincerity, i.e. the speaker has to believe that the proposition he utters is true.

In IAT, the connection between an act in a dialogue and its content in the dialogue domain is warranted by the authorization granted to the performer of this act (the concept of the authorization component for ethotic inferential structures was proposed in (Budzynska 2010). That is, the content of the act will be transferred into the dialogue domain and, possibly, accepted as true, only if the speaker is allowed to perform this act. The authorization is dependent on the type of the illocutionary connection. More specifically, a given type of illocutionary connection places particular obligations on the speaker. This paper does not aim to provide a full list of such obligations for all of the illocutionary forces. To show how the assertive interpretation of ethotic circularity can be represented, it is sufficient to focus our attention on the obligation of speaker's credibility for the illocution of simple assertion. A condition expressing such an obligation (e.g. "Bob is credible" for asserting instance \#1 and \#2 in Fig. 1) will be called an ethotic condition.

Inference Anchoring shows that the argumentative illocutionary connection (see e.g. the node arguing instance \# 1 in Fig. 1) is structurally distinct from e.g. the assertive connection, since it begins (is anchored) at the transition between communicative acts (see the node transition instance \#2) rather than at one communicative act and aims at inference (see the node argument from consequences instance \#1) rather than at an act's single propositional content. It reflects the social nature of argumentation: it is invoked by a doubt (conflict) expressed in Wilma's utterance (4-b), and provided by Bob's utterance (4-c) which aims to remove the doubt (resolve the conflict).

Argumentation (inferential argument) is not the only relational speech act-the same structure, for example, is also seen in explanation and undercutter (attacking argument). ${ }^{4}$ Observe that this approach is different than segmented discourse representation

\footnotetext{
4 An undercutter is a counter-argument that attacks the inferential link between premises and conclusion of another argument (Pollock 1995). Although an undercutter is referred to as an argument, it is not an argument in the inferential sense. That is, the inferential type of argument (argument pro-) is reasoning that links its premise(s) with its conclusion via a relation of inference (support), while the undercutter is the attacking type of argument (argument con-) which links propositions (that are neither its "premises" nor its
} 
theory (SDRT) (Asher and Lascarides 2003). In the latter, all speech acts are relational independently of whether or not their contents are inferentially related to each otherone of the contents is a dialogical context for another, no matter if it is a premise (as in explanation) or a proposal (as in refusal). In IAT, some of the speech acts are relational (if their illocutionary force refers to the relation between propositions, like in argumentation or explanation), and others are non-relational (if the illocutionary force refers to only one proposition, like in assertion or refusal).

\subsection{Illocutionary versus inferential structures}

There are some formal similarities between an illocutionary structure containing a simple assertion and an ethotic inferential structure. In consequence, the illocutionary connection linking together an assertion with its propositional content may seem to be in fact the inferential connection linking together a premise(s) with a conclusion, for both of them are structurally the mappings from a power set of sentences into a set of sentences. Yet despite this superficial structural resemblance they are different communicative phenomena with different properties.

One of the most important distinctions provided by speech act theory is that between the utterances' illocutionary forces and reasoning performed by the speaker. There is always some kind of relation between the utterance and its content, but this relation does not necessarily have to have inferential character; it can simply manifest the illocution of the utterance. Moreover, even if the speaker performs an argument, the inference produced will be different from the argumentative illocutionary force of the act itself. Inference Anchoring adopts this idea and allows the representation of both illocutionary structures (building on rich models of illocution provided by speech act theory) and inferential structures (building on rich models of inference provided by argumentation theory). As a result, in IAT it is possible to differentiate between those structures, but also to express their interactions.

What is more, many other speech acts, in particular those that do not belong to the class of representatives, do not manifest this superficial formal resemblance to the inferential structure at all. For example, Wilma's challenge (4-b) cannot be modelled as being connected to its propositional content "Wilma should not eat too much salt" on the basis of inferential connection, for the proposition "I should not eat too much salt" cannot be derived from the propositions describing Wilma's act and her credibility: "I say that why should I not eat too much salt and I am credible". Nevertheless Wilma's communicative act and its content are still linked together, which is represented in IAT by the illocutionary connection (see e.g. the node challenging instance \# 1 in Fig. 1). The existence of the illocutionary connection brings some obligations on Wilma, e.g. she is obliged to want (desire) Bob to provide justification for why she should not eat too much salt.

Footnote 4 continued

"conclusion") via a relation of attack (modelled e.g. as in an Abstract Argumentation Framework (Dung 1995)). 
Another possible reason for confusing illocutionary structures with ethotic inferential structures could be the presence of the ethotic component in both of them. The ethotic component of illocutionary connection can be mistakenly taken to be a premise of an ethotic or position-to-know argument referring to the speaker's ethos, while in fact it is the ethotic condition on this assertion. As a result, the utterance "I'm credible" may be interpreted just as a simple assertion, however, the utterance is still circular, for the content of this act is the same as its ethotic condition.

\subsection{Ethos, illocution and ethotic argument}

IAT shows that the speaker's ethos should not be limited to ethotic argumentation, since it can be considered in the context of many different speech acts, not only argumentation. An utterance may be just a simple assertion (e.g. "Bob said, $A$ ") and still the speaker's credibility can be evaluated within the illocutionary structure that this assertion produces.

In order to describe the interaction between ethotic inferential structures, illocutionary structures and the ethotic component of a speaker's credibility, consider the dialogue with explicit ethotic argument:
a. Bob said, $A$
b. Wilma said, Why?
c. Bob said, Because John said so.

Bob's first utterance (5-a) is linked with its propositional content $A$ via an illocutionary connection asserting instance \#1 (see Fig. 2). Wilma's utterance (5-b) is linked with the same content but via a connection with different illocutionary force (challenging instance \#1). Bob's second utterance (5-c) is linked with its propositional content "John said A" via an illocutionary connection asserting instance \#2, however, since this content is still a report of (John's) utterance, it will be again linked with its content, i.e., A, via an illocutionary connection asserting instance \#3. Since the utterance (5-c) was performed as an argumentative response to Wilma's challenge, the transition (transition instance \#2) connecting the challenge and the respond serves as an anchor for the argument captured by the inference (inference node \#1) via an instance of the illocutionary force of arguing (arguing instance \#1).

Bob's ethotic argument consists of premises, "John is credible", "John said, A", an inference ethotic argument instance \#1, and a conclusion A. Since this inferential structure has an ethotic character, the parallel illocutionary structure can be identified in the diagram. It consists of inputs "John is credible", "John said, $A$ ", an illocutionary connection asserting instance \#1, and an output $A$. The component describing the speaker's ethos "John is credible" is involved both in the (ethotic) inference structure and in the illocutionary structure.

The notion of ethos is broader than the notion of ethotic argumentation, for the speaker's ethos is considered not only with respect to ethotic arguments (e.g. as condition on ethotic argument instance \#1), but also with respect to, e.g., simple assertions (e.g. as a condition on asserting instance \#1). Furthermore, Inference Anchoring emphasizes that the credibility here, not just of one, but of two speakers is involved 


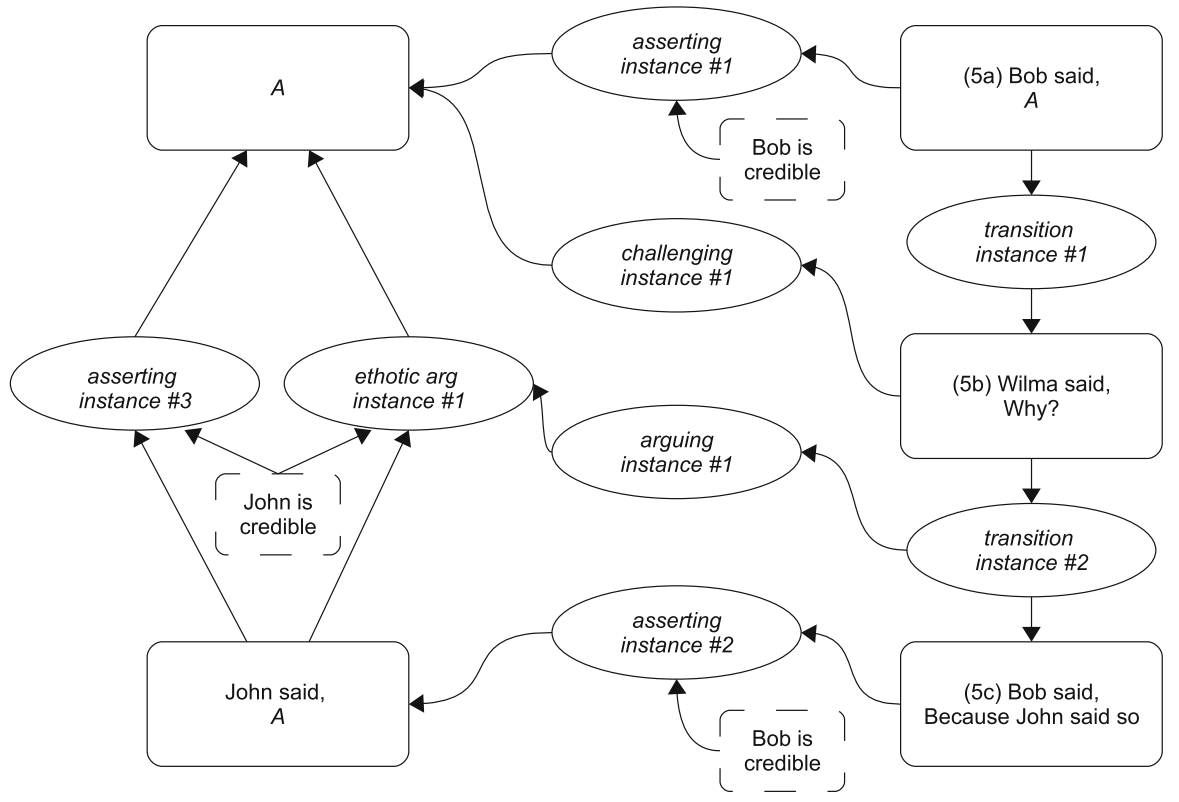

Fig. 2 The representation of ethotic argument in Inference Anchoring Theory

in ethotic arguments. That is, not only the ethos of the speaker to whom the argument appeals (i.e., John) plays a role here, but also the ethos of the speaker who performs the argument (i.e., Bob) is important. As a result, it is possible to distinguish in IAT both an "internal" ethotic attack, i.e. an attack on the credibility of the speaker to whom the argument appeals (John), but also an "external" attack on the credibility of the argument's sender (Bob). For example, Wilma could attack Bob's argument in the next move either by saying "John is not credible" (an "internal" attack) or "You (Bob) are not credible" (an "external" attack).

To conclude, an illocutionary structure consists of: (i) an illocutionary connection; (ii) its explicit input, which is an utterance or relation between utterances; (iii) its implicit inputs which express conditions on the illocutionary connection (including ethotic conditions); and (iv) an output, which is a proposition or relation between propositions (the utterance's contents). An ethotic structure is any structure that has a component describing the speaker's ethos. Both illocutionary structures and ethotic arguments are ethotic structures, since both contain a condition of the speaker's credibility.

\section{Non-argumentative ethotic circularity}

Having introduced the concept of illocutionary connection from IAT, we will now address the problem of how to represent utterances which contain ethotic circularity of a non-argumentative nature. 


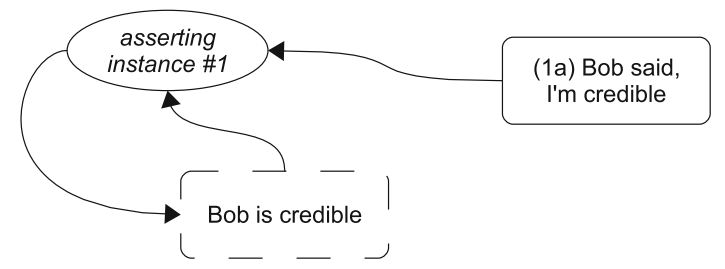

Fig. 3 The representation of circularity in self-referential statement

\subsection{Ethotic self-reference}

The first example of a non-argumentative ethotic cycle is provided by the selfreferential sentence:

(1) a. Bob said, I'm credible.

Bob's utterance (1-a) is connected to its content "Bob is credible" via an assertive illocutionary connection (Fig. 3) which in turn has as an input the condition of Bob's credibility. As a result, there is a structural (circular) dependency between (1-a)'s content and the ethotic condition of (1-a)'s illocutionary connection, in the same way as there is a structural dependency between a premise and a conclusion in the inferential structure: " $A$, because $A$ ".

Yet, here, the circularity is not created within an inferential structure (i.e., in an ethotic argument). It has a purely ethotic nature, for the cycle is created exclusively within illocutionary structure and is related to the basic communication phenomenon of making the acceptance of a message dependent on the credibility of its sender. The proposition "Bob is credible" appears twice, however, not as a premise and a conclusion of ethotic argument, but as an implicit input (i.e. as an ethotic condition on the illocutionary connection created by the utterance (1-a)) and as an output of illocutionary connection (i.e. as the content of this utterance). The cycle is obtained, since the output and the input, which here happen to be the same sentence, are structurally related to each other by means of an illocutionary connection.

\subsection{Embedded testimony}

The model of anchoring inference provides also an intuitive representation for the circularity in the utterance (2-a).

(2) a. Bob said, Ann said I'm credible.

The utterance (2-a) is connected to the content "Ann says Bob is credible" and the illocutionary connection between them is authorized by Bob's credibility (see Fig. 4). This proposition is, however, still a report of (Ann's) speech act, and therefore it is linked with the content "Bob is credible" on the assumption that Ann is credible. As a result, the structural, circular dependency is created between the content of Ann's testimony and the ethotic condition on the illocutionary connection asserting instance \#2 of Bob's testimony about Ann's testimony. 


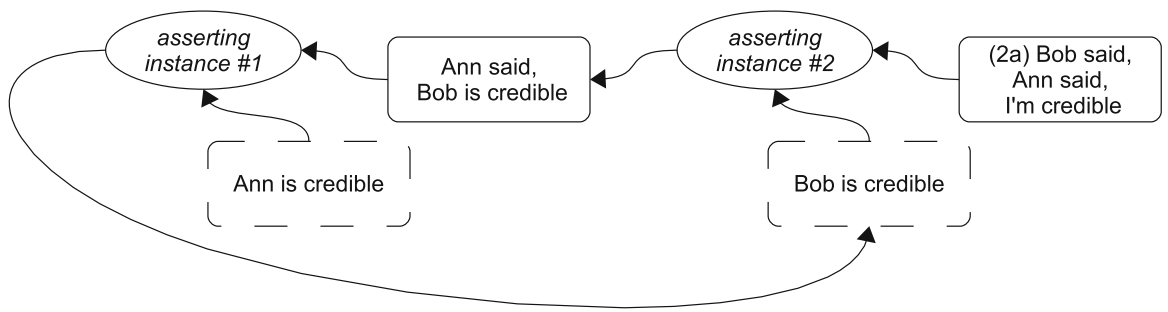

Fig. 4 The representation of circularity in the embedded testimony case

Observe that Ann's credibility does not participate in the cycle in a direct way. Assume that the hearer uses illocutionary structures as a ground for accepting the utterances' propositional contents. In order to accept Bob's credibility, Ann's testimony can be used, which is then accepted on the basis of Bob's credibility. Still, there is a dependency between the credibility of Ann and Bob, since their testimonies are embedded. The evaluation of Ann's credibility is dependant on the evaluation of Bob's credibility. If his credibility is questioned, then the illocutionary connection to the report of what she said will be suspended and her credibility will not be evaluated (we will not accept that she confirmed Bob's credibility, since Bob could mislead us). But once his credibility is, on some other grounds (other than Ann's confirmation), accepted, then we can question her credibility. This licenses two types of responses for (2-a)— the hearer may say either "Why should I believe you?" (questioning Bob's credibility) or "Why should I believe Ann?" (questioning Ann's credibility).

\section{Multi-type ethotic cycles: Hamblin's example}

One well-known example of ethotic circularity is introduced in (Hamblin, 1970, p. 34) and later analysed in (Walton 2006):
a. Manager said, Can you give me a credit reference?
b. Smith said, My friend Jones will vouch for me.
c. Manager said, How do we know he can be trusted?
d. Smith said, Oh, I assure you he can.

In (6), Smith commits the fallacy of dependency begging the question: he supports his credibility with Jones' credibility, and then supports Jones' credibility with Smith's credibility.

In order to represent all aspects of circularity in (6), again the framework of Inference Anchoring Theory will be adopted. We will show that IAT allows the representation of different types of (6)'s ethotic cycles in one robust model. The theory shows that circularity is obtained not only on argumentative structures (what is only possible within the framework of argumentation theory, if the argumentative interpretation of all assertions in (6) is assumed), but also on illocutionary structures. Before we present how IAT can be applied to analyse the dialogue (6), the standard "argumentative" representation will be discussed first. 
Following Walton's reconstruction of (6), assume that at the beginning of the dialogue Smith utters "My credit is good" (see (Concl) in (Arg3)). Further, this utterance is interpreted as a speech act of (ethotic) argument with the main conclusion: "My credit is good" and two premises: "Smith said that his credit is good" $\left(\mathrm{P}_{1}\right)$ and "Smith is credible" $\left(\mathrm{P}_{2}\right)$. The Manager's challenge requesting a credit reference (6-a) makes Smith support his credibility with the report on Jones' testimony (6-b) which is reconstructed as an ethotic argument: "Jones said that Smith is credible" $\left(\mathrm{P}_{2.1}\right)$, and "Jones is credible" $\left(\mathrm{P}_{2.2}\right)$. Finally, in response to the Manager's questioning Jones' credibility (6-c), Smith supports it by confirming that Jones can be trusted (6-d). That is, according to Walton's ethotic argumentation scheme, Jones' credibility is justified by two premises: "Smith said that Jones is credible" $\left(\mathrm{P}_{2.2 .1}\right)$, and "Smith is credible" $\left(\mathrm{P}_{2.2 .2}\right)$. As a result, the circularity is obtained since Smith's credibility $\left(\mathrm{P}_{2}\right)$ is inferred from Smith's credibility $\left(\mathrm{P}_{2.2 .2}\right)$. The structure of the argument in (6) according to Walton's model is thus following:

\section{Argument (Arg3)}

(Concl) Smith's credit is good.

$\left(\mathrm{P}_{1}\right)$ Smith said that his credit is good.

$\left(\mathrm{P}_{2}\right)$ Smith is credible.

$\left(\mathrm{P}_{2.1}\right)$ Jones said that Smith is credible.

$\left(\mathrm{P}_{2.2}\right)$ Jones is credible.

$\left(\mathrm{P}_{2.2 .1}\right)$ Smith said that Jones is credible.

$\left(\mathrm{P}_{2.2 .2}\right)$ Smith is credible.

We could ask now who is performing the implicit ethotic argument: "Smith's credit is good, since Smith says so and he is credible"- the speaker or the hearer? In fact, in the context of this dialogue only the first option is possible. Assume that the Manager makes the assertions with contents $\left(\mathrm{P}_{1}\right)$ and $\left(\mathrm{P}_{2}\right)$ from which he then concludes that Smith's credit is good. Following the common assumption in argumentation theory, he has to accept the premises of this argument, in particular he has to accept Smith's credibility described in $\left(\mathrm{P}_{2}\right)$. But then, the utterance (6-a) becomes problematic. If we interpret it as a challenge on Smith's credibility (i.e., the request to provide an argument supporting Smith's credibility), then we have to allow the speaker to challenge his own argument that he performed in the dialogue one move earlier. Alternatively, we could claim that (6-a) is some other speech act. But then it would be not clear how to understand Smith's utterance (6-b) — why he provided argument supporting his credibility with Jones' credibility if he was not requested to do that (i.e. if his credibility was not previously challenged in (6-a)).

Argumentation theory can be, however, used to represent the circularity in (6) only if we assume the argumentative interpretation of Smith's utterance "My credit is good", i.e. if we assume that in saying "My credit is good," an act of ethotic argumentation was provided: (Concl), since $\left(\mathrm{P}_{1}\right)$ and $\left(\mathrm{P}_{2}\right)$. On the other hand, if Smith's utterance "My credit is good" is interpreted as a simple assertion (not supported by ethotic premises $\left(\mathrm{P}_{1}\right)$ and $\left.\left(\mathrm{P}_{2}\right)\right)$, the sentence "Smith is credible" will not repeat any more and the cycle will not be obtained. In other words, the circularity in (6) can be represented using argumentation theory, if we assume that Smith's utterance "My credit is good" is in fact a speech act of ethotic argument provided by Smith himself. Yet there is no reason 
not to allow a different interpretation of this utterance. Similarly to the self-referential sentence in (1) and embedded testimony in (2), Smith could simply assert "My credit is good" not trying to provide an argument for it.

In the next sections, we will show that IAT can be applied to provide a model for the fallacy of begging the question given assertive interpretation of Smith's first utterance (Sect. 5.2). Moreover, we will demonstrate that in this dialogue there is not only circularity on inferential structures, but also circularity on illocutionary structures alone; in this case there are two such cycles (Sects. 5.3, 5.4). But first, the IAT-model of the dialogue (6) will be described (Sect. 5.1).

\subsection{Extended representation of Hamblin's example}

In order to represent all aspects of circularity in (6), again the framework of Inference Anchoring Theory will be adopted. To remove the ambiguity of how the dialogue (6) begun, a revised version will be analysed:
z. Smith said, My credit is good.
a. Manager said, Can you give me a credit reference?
b. Smith said, My friend Jones will vouch for me.
c. Manager said, How do we know he can be trusted?
d. Smith said, Oh, I assure you he can.

The first utterance in (6)' is connected to its propositional content "Smith's credit is good" (see the four boxes towards the top of Fig. 5). The connection requires Smith to be authorized to perform the assertion including the condition of his credibility. The utterance (6-a)' challenges the content of the previous act "Smith's credit is good" (the interpretation that the Manager directly challenges Smith's credibility is also possible, but we do not consider that interpretation in this analysis). In response, Smith performs assertion (6-b)' with the content, "Jones says that Smith is credible" (see asserting instance \#2 in Fig. 5). Yet this proposition is a report of Jones' speech act with the content "Smith is credible". The illocutionary connection (i.e., asserting instance \#5 in Fig. 5) has as a condition Jones' credibility. Moreover, the same report on Jones' assertion serves as an argument supporting Smith's credibility (in this case, Jones' words are used argumentatively, i.e. as an ethotic argument (see rule instance \#1 in Fig. 5)). As a result, the propositions, "Jones says, Smith is credible" and "Smith is credible" are linked both via an illocutionary connection (asserting instance \#5) and via an inference (rule instance \#1).

The next challenge (6-c)' questions Jones' credibility. Smith's reply (6-d)' is an assertion which is linked to the content "Jones is credible". The illocutionary connection requires Smith's credibility to authorize the performance of this assertion. Again, the propositions, "Smith said that Jones is credible" and, "Jones is credible" create an ethotic argument. In consequence, they are involved both in an illocutionary structure (asserting instance \#4) and in an inferential structure (rule instance \#2). 


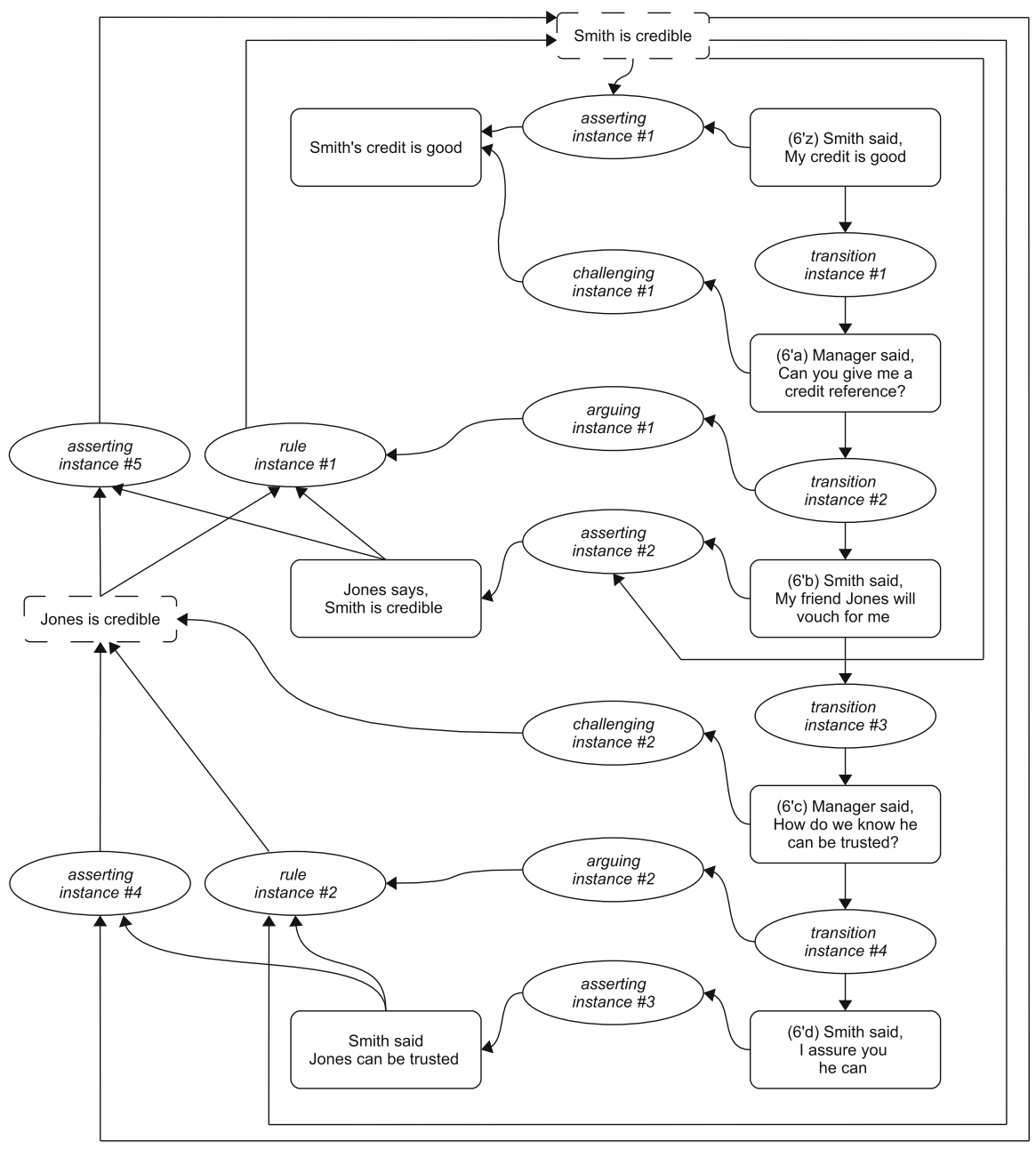

Fig. 5 Hamblin's example according to Inference Anchoring Theory

\subsection{Cycle on ethotic inferential structures}

The first cycle in (6) ${ }^{\prime}$ is argumentative and is emphasized in the version of Fig. 5 presented in Fig. 6. The reconstruction is similar to the reconstruction proposed within the framework of argumentation theory (see (Arg3.)) with one exception-assertive (non-argumentative) interpretation of the utterance (6-z)' is assumed. That is, Smith's credibility plays an important role here even though we do not assume that Smith tried to prove that his credit is good with an ethotic argument referring to his credibility. Smith's credibility is now not a premise of an argument, but a condition of the assertive illocutionary connection for his claim about credit (see asserting instance \# 1 in Fig. 6). 


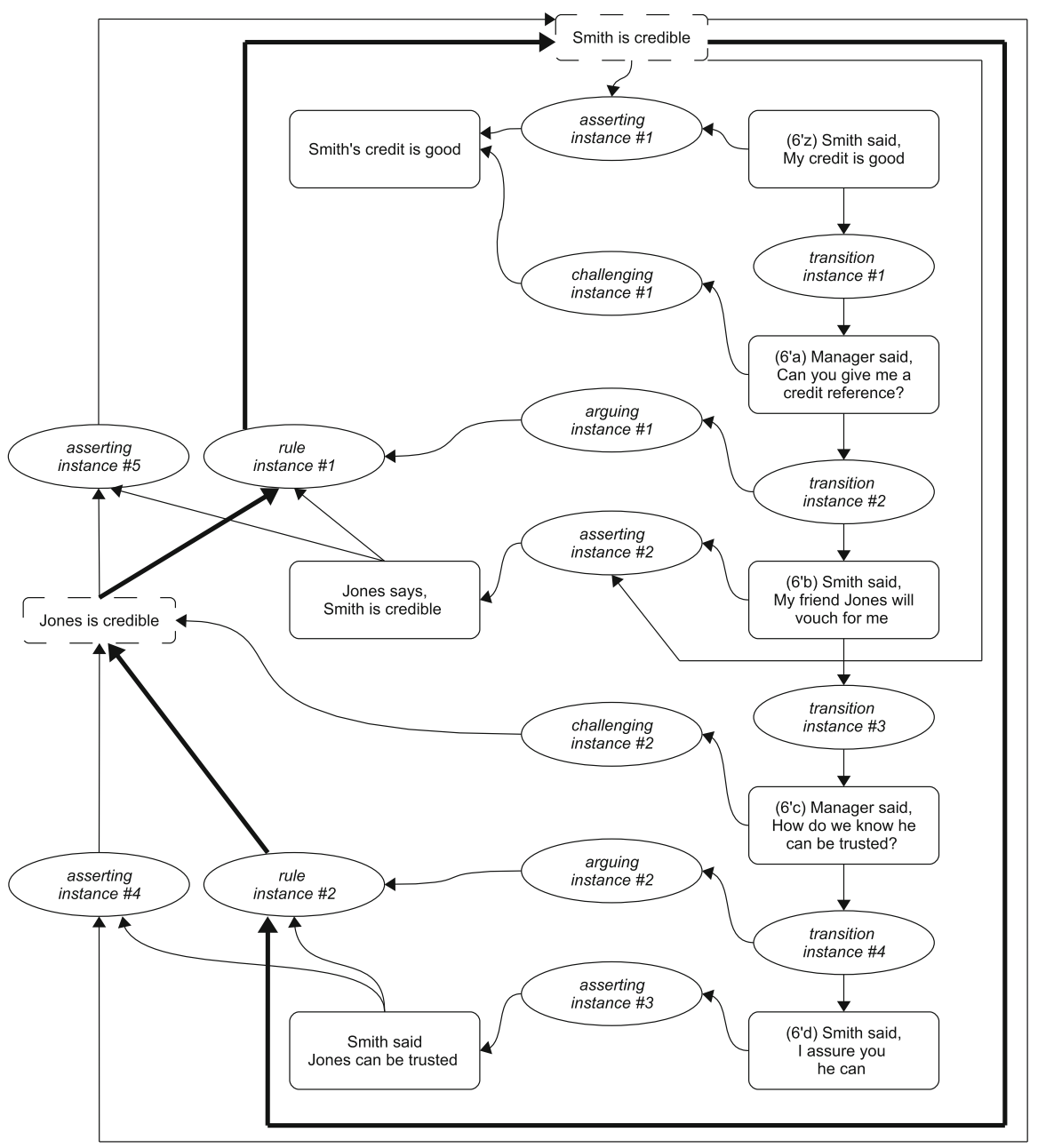

Fig. 6 The cycle on inference structures

After performing the assertion (6-z)' and the Manager's challenge (6-a)', Smith formulates an argument supporting his credibility: "Jones says, Smith is credible" (the inferential step denoted as rule instance \#1). In order to accept the conclusion, its implicit premise "Jones is credible" has to be accepted. In response to the Manager's second challenge on Jones' credibility (6-c)', Smith provides a second ethotic argument, "I say that Jones can be trusted", which involves Smith's credibility as a condition (see the condition of rule instance \#2). As a result, a cycle on ethotic argumentation (inferential structure) is obtained (shown as the bold-line path in Fig. 6).

Even if $(6-z)^{\prime}$ is not interpreted argumentatively, Inference Anchoring Theory can still include in the model of $(6)^{\prime}$ the sentence, "Smith is credible" which is necessary for the ethotic circularity to be represented. According to IAT, the dialogue contains 
not three ethotic arguments as the model of argumentation theory assumes (see Arg3), but two arguments (see the nodes rule instance \#1 and \#2). Yet the ethotic component of Smith's credibility is present in the model, since it constitutes (not the premise but) the condition of illocutionary connection obtained from Smith's assertion (6-z)'.

Further, it is assumed here that the other two of Smith's utterances are differentthey have an argumentative function. The act (6-b)' is performed with the intention of providing an argument ("Jones says, Smith is credible") supporting the claim "Smith is credible", necessary to authorize the link with the content challenged by the Manager. Similarly, the utterance $(6-\mathrm{d})^{\prime}$ is performed with the intention of providing ethotic argument ("Smith asserts that Jones is credible") supporting the claim, "Jones is credible," necessary to authorize the connection between Jones' testimony about Smith's credibility and the content of this testimony. As a result, the implicit ethotic component of Smith's credibility associated with both the speech act (6-z) ${ }^{\prime}$ and the ethotic argument rule instance \#2 allows the argumentative cycle to be represented. Still, the cycle has an inferential (not illocutionary) character, for the path creating a cycle leads not through illocutionary connections but through inference nodes.

\subsection{Cycle on illocutionary structures}

The second cycle in Hamblin's example has an ethotic rather than inferential nature as it is created exclusively by the illocutionary components, and is shown in the version of Fig. 5 presented in Fig. 7. The ethotic condition "Smith is credible" in the illocutionary connection asserting instance $\# 1$ is linked with the ethotic condition "Jones is credible" via the illocutionary connection asserting instance \#5 related to the utterance (6-b)'. Then, this condition "Jones is credible" is again linked with the ethotic condition "Smith is credible" via the illocutionary connection asserting instance \#4 related to the utterance $(6-d)^{\prime}$. As a result, a structural (circular) illocutionary dependence is obtained.

The existence of both inferential and illocutionary cycle in this dialogue means that Smith does not only circularly argue, but also circularly asserts. In other words, if Smith's utterances were performed in entirely non-argumentative context (e.g. such as in the dialogue: Smith said, My friend will vouch for me; Manager said, Is Jones credible; Smith said, Yes), the dialogue would still contain cycle. Yet, since the cycle would be illocutionary, it could not be represented by standard models of argumentation theory.

The ethotic cycle is created whenever a path leads through illocutionary connections and the first node of the path is the same as the last one. The fallacy of ethotic circularity is committed in a dialogue $D$ if in the diagram representing $D$ there is a path via illocutionary nodes and nodes representing propositions, and this path creates a cycle.

The question we can now ask is when an ethotic structure commits the fallacy of ethotic begging the question. First, observe that in an ethotic argument an inferential circular structure is always accompanied by an illocutionary circular structure, since the premise in an inferential structure, " $i$ said $A$ " is a report on the performance of a speech act and therefore generates an illocutionary connection with the propositional content $A$ (see Sect. 3.3). As a result, the ethotic circular argumentation can be easily 


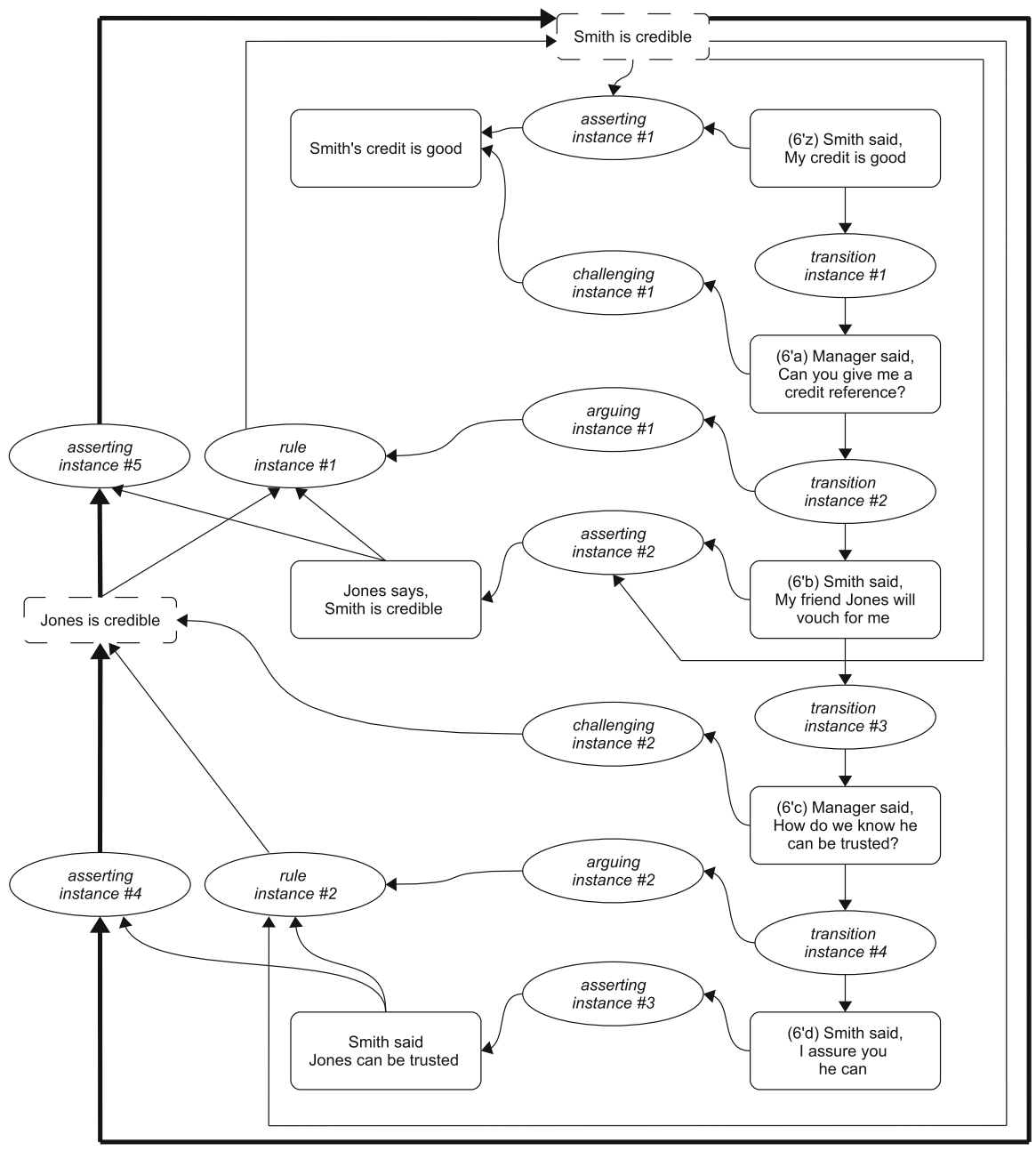

Fig. 7 The cycle on illocutionary structures

identified, since it involves two cycles on both illocutionary and inferential nodes (as in Hamblin's example).

Next, according to (Walton 2006), not every instance of circular reasoning commits the fallacy of begging the question. Circular reasoning commits the fallacy of begging the question iff it fails to fulfil its function of removing doubt expressed in the conclusion and this function is associated only with argumentation. Once reasoning is performed through a speech act other than argumentation, e.g., in explanation, the circularity can also be fallacious, but for some reason other than begging the question. For example, circular explanation may fail to fulfil its function of increasing the understanding on the issue queried. In (Bex and Budzynska 2010), it is proposed how these two speech acts can be differentiated in the model: the same inferential structure can be an output for an illocutionary connection that is of an argumentative 
type or of an explanatory type. Thus, in order to capture the begging-the-question character of Smith's argument in Hamblin's example, the inferential structures: rule instance \#1 and rule instance \#2, have to be a target of argumentative illocutionary force (i.e. arguing instance \#1 and arguing instance \#2, respectively).

Thus we say that a circular ethotic fallacy is ethotic circular argumentation (ethotic begging the question) iff there are inferential nodes that fulfil the following conditions: (i) for each inferential node there is an illocutionary node with argumentative illocutionary force such that the inferential node is an output for this illocutionary node, (ii) the path via inferential nodes and nodes representing propositions creates a cycle, and (iii) for each inferential node there is an illocutionary node such that each input of this illocutionary node is an input of the inferential node and an output of the illocutionary node is an output of the inferential node.

The first condition guarantees that inferences creating a cycle have argumentative (and not, e.g., explanatory) illocutionary force, since an illocutionary node initiated by a dialogue and targeting at an inferential node has to have this specific force (see e.g. arguing instance \#1 and \#2 targeting at rule instance \#1 and \#2, respectively, in Fig. $6)$. The second condition requires a cycle on inferential structures such as e.g. a cycle via the path in Fig. 6: the node Bob is credible - the inferential node rule instance \#1- the node Jones is credible - the inferential node rule instance \#2-the node Bob is credible. The last condition assures that the argumentation is ethotic, since each inferential node in a cycle is accompanied by a parallel illocutionary node. They are parallel, because both of them has the same inputs and output. For example, the inferential node rule instance \#1 is "parallel" with the illocutionary node asserting instance \#5, since both of them has as an input the nodes: Jones is credible, and Jones says, Smith is credible; and as an output the node: Smith is credible (see Fig. 7).

The self-referential utterance, embedded testimony and Hamblin's example commit the fallacy of ethotic circularity. For assertive interpretation of the utterances (1-a), (2-a) and $(6-z)^{\prime}$, the key difference between those three examples is that the two first dialogues contain ethotic cycles, but they are purely illocutionary, while the last one also commits the fallacy of begging the question.

\subsection{And a third cycle}

Hamblin's example contains also one more ethotic circularity - a circularity of embedded testimony. This cycle is created by Smith's utterance (6-b)', since in order to accept what Jones testified (i.e. that Smith is credible), we have to accept Smith's credibility beforehand. This communication scenario is similar to Bob's testimony about Ann's testimony in example (2). Figure 8 shows the path which creates this circularity: the propositional content links with (6-b)' via illocutionary connection asserting instance \#2 is "Jones says, Smith is credible". Since it is a report of Jones' speech act, it is linked via illocutionary connection asserting instance \#5 with its content "Smith is credible". Yet "Smith is credible" is an ethotic condition of the illocutionary connection asserting instance \#2, where the path began. As a result, the circularity on illocutionary structures is obtained, since the path leads through the illocutionary connections. 


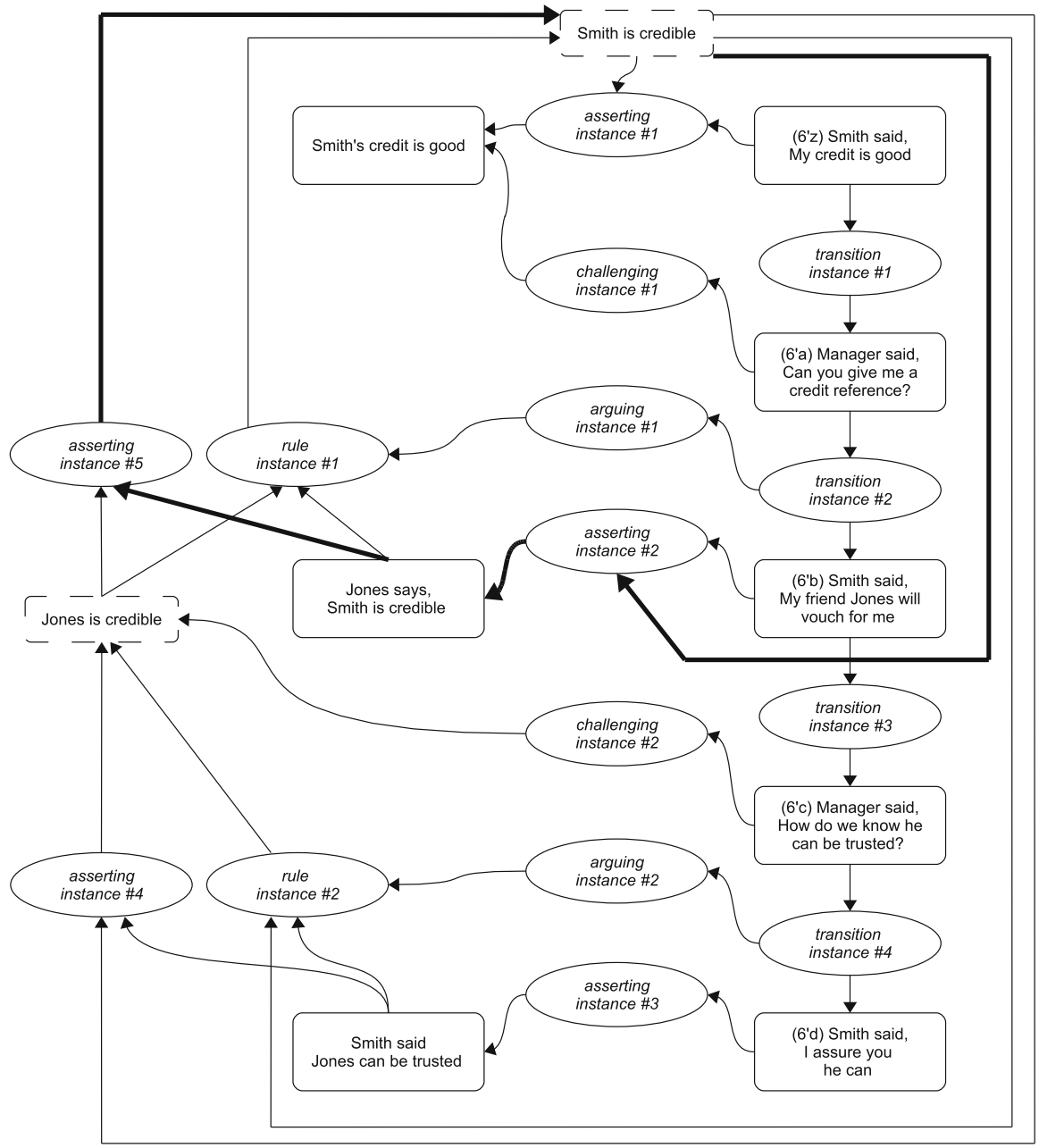

Fig. 8 The cycle on embedded testimony

To sum, the inferential account and IAT account of Hamblin's example are different for various reasons. First, we showed that the circularity of $(6)^{\prime}$ can be demonstrated even under the assertive interpretation of (6-z) (Sect. 5.2). Second, IAT reveals the existence of not one, but several cycles in this dialogue: not only the ethotic begging the question (Sect. 5.2), but also cycle on illocutionary structures (Sect. 5.3) and the cycle of embedded testimony (described in this section).

\section{Conclusions}

This paper has proposed a model which allows the representation and analysis of ethotic circularities not only in argumentative utterances but also in assertive utterances. 
The ethotic cycles are reconstructible, since both purely ethotic structures (illocutionary connections) and ethotic inferential structures (ethotic reasoning) involve the ethotic condition of the speaker's credibility.

In the structure of any circular ethotic fallacy, a path via illocutionary nodes can be identified and the path's first node is the same as the last one. The circular ethotic fallacies can be of two types. First, a purely illocutionary circularity has the cyclic path leading exclusively via illocutionary nodes (i.e. no inferential node is involved in the cycle). The self-referential sentence (1) and the embedded testimony (2) under an assertive interpretation are both examples of this type of ethotic circularity. The second type of circular ethotic fallacy is an ethotic circular argument (ethotic begging the question) in which the cyclic path via inferential nodes can be identified as in Hamblin's example.

Explicit reference to the speaker's ethos is very common in natural contexts as is well recognized in disciplines such as rhetoric, psychology and social science (see e.g. Aristotle 1991; Petty and Cacioppo 1986; Goldman 2010; Sperber et al. 2010). Only in argumentation theory is ethos studied as a part of communication structures, but until now it has not been represented satisfactorily and has been mostly limited to the study of different versions of ethotic arguments. This paper shows how the standard approach needs to be extended in order to reconstruct ethotic circularities of a non-argumentative nature. A model with purely ethotic components finds many applications wherever there is a need to represent an explicit reference to the speaker's credibility, as e.g. in the rhetorical ad hominem technique in which the ethos of the speaker (and not the logos of his speech) is directly attacked.

Acknowledgements The author gratefully acknowledges the support from Polish Ministry of Science and Higher Education under grant N N101 009338. The author would also like to thank Chris Reed for discussion and inspiring comments, and would like to express thanks to the reviewers for detailed, constructive and thoroughly helpful comments on earlier drafts of this paper. Any errors that may remain are, of course, entirely the responsibility of the author.

Open Access This article is distributed under the terms of the Creative Commons Attribution License which permits any use, distribution, and reproduction in any medium, provided the original author(s) and the source are credited.

\section{References}

Aristotle. (1991). On Rhetoric (G. A. Kennedy, Trans.). New York: Oxford University Press.

Asher, N., \& Lascarides, A. (2003). Logics of conversations. Cambridge: Cambridge University Press.

Beall, J. C., \& Glanzberg, M. (2011). Liar paradox. In E. N. Zalta, (Ed.), The stanford encyclopedia of philosophy, Spring Edition.

Bex, F., \& Budzynska, K. (2010). Argumentation and explanation in the context of dialogue. Proceedings of 10th International Conference on Computational Models of Natural Argument, pp. 1-4

Brinton, A. (1986). Ethotic argument. History of Philosophy Quarterly 3, 245-257

Budzynska, K. (2010). Argument analysis: Components of interpersonal argumentation. In 18. Frontiers in Artificial Intelligence and Applications., pp. 135-146. Amsterdam: IOS Press

Budzynska, K., \& Kacprzak, M. (2008). A logic for reasoning about persuasion. Fundamenta Informaticae, (85), 51-65. Amsterdam: IOS Press

Budzynska, K., \& Reed, C. (2011). Whence inference?. University of Dundee Technical Report

Dung, P. M. (1995). On the acceptability of arguments and its fundamental role in nonmonotonic reasoning, logic programming, and n-person games. Artificial Intelligence, 77, 321-357 
Goldman, A. (2010). Social epistemology. In E. N. Zalta, (Eds.) The stanford encyclopedia of philosophy, Summer 2010 Edition.

Hamblin, Ch. L. (1970). Fallacies. London: Methuen.

Petty, R. E., \& Cacioppo, J. T. (1986). Communication and persuasion: Central and peripheral routes to attitude change.. New York: Springer.

Pollock, J. (1995). Cognitive Carpentry. Cambridge, MA: MIT Press.

Prakken, H. (2006). Formal systems for persuasion dialogue. The Knowledge Engineering Review, 21, $163-188$

Reed, C. (2006) Representing dialogic argumentation. Knowledge Based Systems, 19(1), 22-31

Reed, C. A., Walton, D., \& Macagno, F. (2007). Argument diagramming in logic, law and artificial intelligence. The Knowledge Engineering Review, 22(1), 87-109.

Reed, C., Wells, S., Budzynska, K., \& Devereux, J. (2010). Building arguments with argumentation: the role of illocutionary force in computational models of argument. In Proceedings of the 3rd International Conference on Computational Models of Argument (COMMA 2010)., pp. 415-426. Amsterdam: IOS Press.

Searle, J. (1969). Speech acts: An essay in the philosophy of language. Cambridge: Cambridge University Press.

Sperber, D., Clement, F., Heintz, C., Mascaro, O., Mercier, H., Origgi, G., \& Wilson, D. (2010). Epistemic vigilance. In Mind and Language, 25(4), 359-393

Walton, D. (1996). Argumentation schemes for presumptive reasoning. Mahwah, NJ: Lawrence Erlbaum Associates.

Walton, D (1998). Ad Hominem arguments. Tuscaloosa: University of Alabama Press.

Walton, D. (1999). The credibility function in multi-agent dialogue systems. Pragmatics and Cognition, 7, 177-203.

Walton, D. (2006). Epistemic and dialectical models of begging the question. Synthese, 152, 237-284.

Walton, D (2009). Dialectical shifts underlying arguments from consequences. Informal Logic, 29, 54-83.

Walton, D., \& Reed, C. (2005). Argumentation schemes and enthymemes. Synthese, 145(3), 339-370.

Walton, D., Reed, C., \& Macagno, F. (2008). Argumentation schemes. Cambridge: Cambridge University Press.

Woods, J., \& Walton, D. (1975). Petitio principii. Synthese, 34, 107-127. 